\title{
Fe(III)-Aqua Complex Mediated Photodegradation of Methylene Blue Dye
}

\author{
Ashfeen Nawar, Md. Ataur Rahman, and Md. Mufazzal Hossain
}

\begin{abstract}
Industrialization in the current times has become extremely rapid. Some of these industries are responsible for discharging dye-containing wastewater into natural water bodies and hence causing environmental deterioration. The purpose of this research is to investigate an inexpensive and easy-to-set-up photodegradation process for the mineralization of methylene blue (MB) dye. The optimum conditions required for maximum degradation of the dye were explored by varying different experimental parameters such as the initial concentration of $\mathrm{Fe}$ (III) and dye, $\mathrm{pH}$ of the reaction mixture, nature of light sources, and intensity of ultraviolet (UV) light. Approximately $97 \%$ photodegradation of methylene blue was recorded at $\mathrm{pH} 2.30$ for the optimum concentration of $\mathrm{MB}$ of $3.00 \times 10^{-5} \mathrm{M}$ and $\mathrm{Fe}$ (III) aqueous solution of $8.00 \times 10^{-4} \mathrm{M}$ when irradiated under UV light of intensity $3.31 \times 10^{-9} \mathrm{Ein}^{-3}$ $\mathrm{s}^{-1}$. Under sunlight, with similar experimental conditions, $73 \%$ degradation of the dye was achieved. This is an environment-friendly, efficient, and low-cost degradation process of methylene blue.
\end{abstract}

Index Terms-Environmental chemistry, Fe(III)-aqua complex, methylene blue, photocatalysis, photodegradation.

\section{INTRODUCTION}

One of the main causes of environmental pollution worldwide is the discharge of dye-containing wastewater effluents into natural water bodies from textile, pharmaceutical, food processing, paper and pulp, and tannery industries [1]. There are a few reasons why their presence poses such a major threat to the surrounding ecosystem. Many of the dyes and their breakdown products are extremely poisonous and cancer-causing agents. If ingested for a longer period of time, they can be very harmful to living organisms. Moreover, a high concentration of textile dyes in water bodies inhibit the reoxygenation capacity of water as well as prevent sunlight from passing through and reaching the plants and organisms living underwater. As a result, the biological activity and photosynthetic process of aquatic life are greatly impaired [2].

Most of the dyes are not biodegradable because of their aromatic structure, and therefore, without proper treatment, they can persist in the environment for a long time [1], [3], [4] Therefore, it is crucial to eliminate the organic dyes from wastewater so that their effect on the environment is minimized. There are numerous conventional methods such as biological, physical, and chemical processes or their combinations commonly employed for the removal of these

Manuscript received August 6, 2020; revised February 18, 2021.

The authors are with the Department of Chemistry, University of Dhaka, Dhaka-1000, Bangladesh (e-mail: ashnawar95@gmail.com, ataur@du.ac.bd, mufazzal@du.ac.bd). pollutants, but they all have several drawbacks, e.g., inefficient dye removal, the formation of toxic by-products, expensive, and time-consuming. Moreover, most of these processes only convert the pollutants from one phase to another, leading to secondary pollution [5], [6].

Advanced oxidation processes (AOPs) are alternative to traditional methods that involve the in situ generation of hydroxyl radical $\left({ }^{\circ} \mathrm{OH}\right)$. These reactive species are capable of mineralizing a broad range of organic pollutants rapidly and nonselectively [7], [8]. The AOPs have been broadly classified into homogenous and heterogeneous systems. Extensive research work has been done using $\mathrm{TiO}_{2} / \mathrm{ZnO}$ as heterogeneous photocatalysts for the degradation of dye and pollutants under an artificial or natural light source. These materials are commonly used because they are photo stable, low priced, and have high redox activity and selectivity [9], [10]. However, one major disadvantage is that it is quite time-consuming and cost-inefficient to separate and recycle the extremely fine catalyst from the wastewater before discharge during large-scale operations.

Several studies have also been carried out using homogenous AOPs such as Fenton's reagent, light-assisted Fenton's oxidation, $\mathrm{H}_{2} \mathrm{O}_{2} / \mathrm{ultraviolet}(\mathrm{UV})$ treatment, and ozonation at high $\mathrm{pH}$ [11], [12]. Despite the many advantages of using the Fenton reagent, the oxidation process might not be considered efficient for large-scale applications because of the toxicity and high cost of the oxidant $\mathrm{H}_{2} \mathrm{O}_{2}$ as well as modulation of $\mathrm{pH}$ during the process [13]. The drawback of the $\mathrm{O}_{3} / \mathrm{UV}$ process is that, in addition to it being cost- and energy-intensive, the ability of UV light to penetrate the solution is hindered by the turbidity of the system. Also, compounds such as nitrate are known to obstruct the absorbance of UV light [14].

Photodegradation of organic pollutants and dyes under artificial or solar light has been studied using $\mathrm{Fe}(\mathrm{III})$ complexes as homogenous photocatalyst. Unlike the Fenton process, it does not involve the use of $\mathrm{H}_{2} \mathrm{O}_{2}$, and hence, this AOP is more environment friendly. Among the different $\mathrm{Fe}$ (III) complexes investigated as photocatalysts, $\mathrm{Fe}(\mathrm{III})$ in aqueous solution (Fe(III)-aqua complex) have several advantages and yielded promising photodegradation results [15], [16]. This process is more economical because $\mathrm{Fe}(\mathrm{III})$ ions are easily found and available in the natural environment. $\mathrm{Fe}(\mathrm{III})$-aqua complex is easier to handle and use because there is no necessity to conduct any intensive or complicated pre-/post-treatment of the dye/catalyst. Therefore, the degradation process photoinduced by $\mathrm{Fe}(\mathrm{III})$-aqua complex can be expected to be efficient for the removal of pollutants from aqueous solution. Other $\mathrm{Fe}(\mathrm{III})$ complexes have also been found to act as efficient photocatalyst in the degradation 
of pollutants and dyes. The Fe(III)-citrate-oxalate binary system has been used for the successful photodegradation of amitriptyline [17]. $\quad \mathrm{Fe}(\mathrm{III})$-oxalate-mediated photodegradation of organophosphorus pesticide diazinon and para-arsanilic acid have also been studied [18], [19].

The hydrolysis of $\mathrm{Fe}(\mathrm{III})$ in dilute aqueous solution is considered to occur through the following scheme [16], [20].Coordinated water molecules have been included here.

$$
\begin{gathered}
{\left[\mathrm{Fe}\left(\mathrm{H}_{2} \mathrm{O}\right)_{6}\right]^{3+}+\mathrm{H}_{2} \mathrm{O} \leftrightharpoons\left[\mathrm{Fe}(\mathrm{OH})\left(\mathrm{H}_{2} \mathrm{O}\right)_{5}\right]^{2+}+\mathrm{H}^{+}} \\
{\left[\mathrm{Fe}\left(\mathrm{H}_{2} \mathrm{O}\right)_{6}\right]^{3+}+2 \mathrm{H}_{2} \mathrm{O} \leftrightharpoons\left[\mathrm{Fe}(\mathrm{OH})_{2}\left(\mathrm{H}_{2} \mathrm{O}\right)_{5}\right]^{+}+2 \mathrm{H}^{+}} \\
{\left[\mathrm{Fe}\left(\mathrm{H}_{2} \mathrm{O}\right)_{6}\right]^{3+}+3 \mathrm{H}_{2} \mathrm{O} \leftrightharpoons \mathrm{Fe}(\mathrm{OH})_{3}+3 \mathrm{H}^{+}}
\end{gathered}
$$

According to a study by Faust and Hoigne [21], $\left[\mathrm{Fe}(\mathrm{OH})\left(\mathrm{H}_{2} \mathrm{O}\right)_{5}\right]^{2+}$ is the predominant monomeric $\mathrm{Fe}(\mathrm{III})$ hydroxyl complex formed in the $\mathrm{pH}$ range of 2.5 to 5.0.

Although other Fe(III) hydroxyl species such as the hexaquo $\mathrm{Fe}$ (III) complex are photoreactive, their quantity is insignificant at $\mathrm{pH} \geq 2.5$. Hence, their contribution to the production of ${ }^{\circ} \mathrm{OH}$ radicals can be ignored. Therefore, by maintaining the $\mathrm{pH},{ }^{\circ} \mathrm{OH}$ radicals are being generated by irradiation of the major $\mathrm{Fe}(\mathrm{III})$-aqua complex $\left[\mathrm{Fe}(\mathrm{OH})\left(\mathrm{H}_{2} \mathrm{O}\right)_{5}\right]^{2+}$.

Upon irradiation, Fe(III)-aqua complex goes through a photochemical process and consequently generates ${ }^{\circ} \mathrm{OH}$ radicals and $\mathrm{Fe}(\mathrm{II})$ through an internal electron transfer.

$$
\left[\mathrm{Fe}(\mathrm{OH})\left(\mathrm{H}_{2} \mathrm{O}\right)_{5}\right]^{2+}+\mathrm{h} v \rightarrow \mathrm{Fe}^{2+}+{ }^{\cdot} \mathrm{OH}+5 \mathrm{H}_{2} \mathrm{O}
$$

$\mathrm{Fe}(\mathrm{II})$ is capable of being reoxidized by oxidants (e.g., dissolved oxygen) to Fe(III) again [22].

$$
\mathrm{Fe}^{2+}+\mathrm{O}_{2}(\mathrm{~h} v) \rightarrow \mathrm{Fe}^{3+}
$$

A synthetic organic dye found in wastewater is methylene blue (MB) also known as methylthioninium chloride, $\mathrm{C}_{16} \mathrm{H}_{18} \mathrm{ClN}_{3} \mathrm{~S}$. It is a thiazine dye and is a formal derivative of phenothiazine.<smiles>CN(C)c1ccc2nc3ccc(N(C)C)cc3[s+]c2c1</smiles>

Fig. 1. Methylene blue dye.

In a recent study, a series of $\mathrm{CuO}$ catalysts were used for the discoloration of $\mathrm{MB}$ in the presence of $\mathrm{H}_{2} \mathrm{O}_{2}$ [23]. Suhaimy and Abdullah [24] conducted a research on the removal of $\mathrm{MB}$ dye from aqueous solution through adsorption using slag from an electric arc furnace. Although the process is fairly efficient in removing MB, the dye still remains in the environment in adsorbed form and can give rise to polluting effects. The slag containing the adsorbed dye would have to undergo further treatment for $\mathrm{MB}$ to be eradicated completely. The photodegradation mechanism of MB in water under UV light was investigated by using $\mathrm{TiO}_{2}$ as photocatalyst. The study concluded that complete mineralization of the dye is possible and the final products of the photodegradation process were identified to be $\mathrm{CO}_{2}$, $\mathrm{SO}_{4}{ }^{2-}, \mathrm{NH}_{4}{ }^{+}$, and $\mathrm{NO}_{3}{ }^{-}$[25].

To the best of our knowledge, no literature has yet been found that investigated $\mathrm{Fe}$ (III)-mediated photodegradation of MB dye. Herein, we present the study of the catalytic efficiency of $\mathrm{Fe}$ (III)-aqua complex as photocatalyst for the mineralization of the MB dye and investigate the optimum conditions required for maximum photodegradation.

\section{EXPERIMENTAL}

\section{A. Chemicals and Reagents}

The analytical grade $\mathrm{MB}$ dye and $\mathrm{Fe}\left(\mathrm{NO}_{3}\right)_{3} \cdot 9 \mathrm{H}_{2} \mathrm{O}$ obtained from MERCK, Germany, were used without any further treatments. MB stock solution of $4.0 \times 10^{-4} \mathrm{M}$ was initially prepared, and further dilutions were made whenever necessary. Solutions of $\mathrm{Fe}\left(\mathrm{NO}_{3}\right)_{3} \cdot 9 \mathrm{H}_{2} \mathrm{O}$ were freshly prepared before every experiment. $\mathrm{NaOH}$ and $\mathrm{HNO}_{3}$ were also obtained from MERCK, Germany.

\section{B. Preparation of the Sample}

A certain volume of $\mathrm{MB}$ and $\mathrm{Fe}\left(\mathrm{NO}_{3}\right)_{3} \cdot 9 \mathrm{H}_{2} \mathrm{O}$ stock solutions were taken in a $100-\mathrm{mL}$ beaker to prepare a reaction mixture of the desired concentration. Because Fe(III) ions form precipitate at a $\mathrm{pH}$ higher than 3.50 , the $\mathrm{pH}$ of the reaction mixture was adjusted and maintained below 3.50 in every experiment. This was done using $0.01 \mathrm{M} \mathrm{NaOH}$ and $0.01 \mathrm{M} \mathrm{HNO}_{3}$.

\section{Photodegradation Procedure}

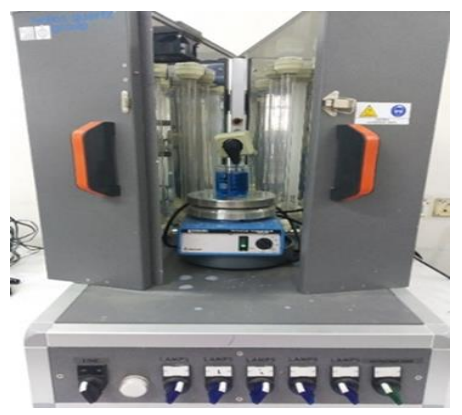

Fig. 2a. UV light source.

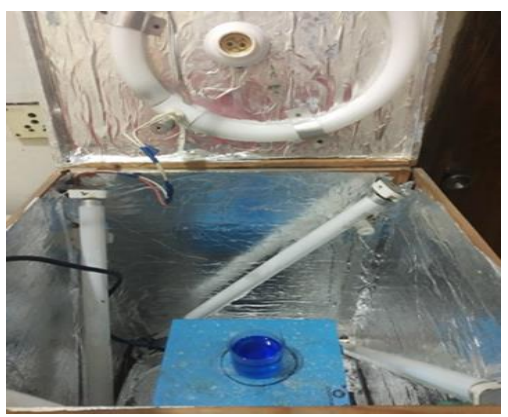

Fig. 2b. Visible light source

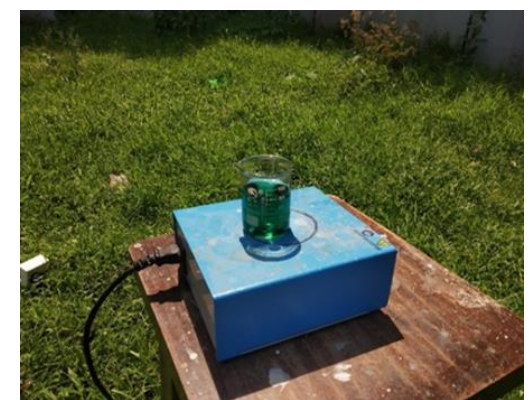

Fig. 2c. Instrumental setup for irradiation in sunlight. 
A typical experiment was done in the following way. The reaction mixture along with a magnetic bar was placed on a magnetic stirrer plate, and the distance of the beaker from the light source was kept constant in every experiment. After every $10 \mathrm{~min}$ for $60 \mathrm{~min}$, a certain portion of the irradiated solution was taken out, and then, the absorbance of the taken solution was measured using a UV spectrophotometer. The effect of three different light sources was investigated. The UV radiation source (Helios quartz group) was composed of 10 lamps (Fig. 2a) emitting monochromatic radiation of $320.0 \mathrm{~nm}$. The light intensity of the UV light source was varied using $2,4,6,8$, and 10 lights corresponding to intensities $1.03 \times 10^{-9}, 1.21 \times 10^{-9}, 1.36 \times 10^{-9}, 2.27 \times 10^{-9}$,

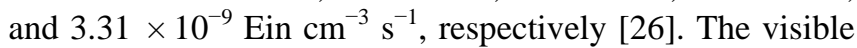
light source was enclosed with a wooden box, inner surfaces of which were covered with aluminum foil paper (Fig. 2b). For solar light, the reactor containing reaction mixture was placed on a magnetic stirrer under sunlight between $12.00 \mathrm{pm}$ and 1.00 pm on sunny days (Fig. 2c) in April 2019 when the temperature was found to be $35{ }^{\circ} \mathrm{C}-38{ }^{\circ} \mathrm{C}$. The percent degradation was calculated using the equation, \%degradation $=\left\{\left(\mathrm{A}_{0}-\mathrm{A}\right) / \mathrm{A}_{0}\right\} \times 100$ where, $\mathrm{A}_{0}$ and $\mathrm{A}$ are the initial absorbance of dye and absorbance of dye after a certain period of irradiation, respectively [27].

\section{RESULTS AND DISCUSSION}

\section{A. Absorption Spectra}

The absorption spectrum of pure MB solution is shown in Fig. 3. MB absorbed strongly in the visible and UV region with $\lambda_{\max }$ at $664.5 \mathrm{~nm}$. All investigations were carried out at this wavelength to monitor the change of concentration of MB in the subsequent experiments. The molar extinction coefficient of the MB dye solution was found to be $55,470 \mathrm{~L}$ $\mathrm{mol}^{-1} \mathrm{~cm}^{-1}$ using a calibration curve.

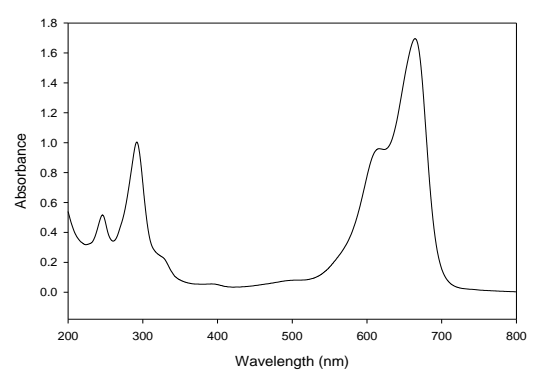

Fig. 3. Spectrum of methylene blue solution (concentration $=3.00 \times 10^{-5} \mathrm{M}$ ).

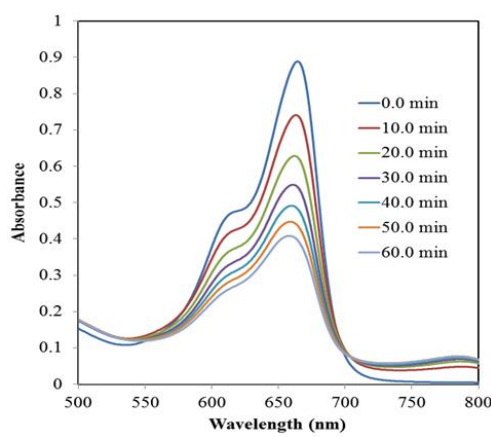

Fig. 4. Spectrum for photodegradation of methylene blue. $[\mathrm{MB}]_{0}=1.50 \times$ $10^{-5} \mathrm{M},[\mathrm{Fe}(\mathrm{III})] 0=8.00 \times 10^{-4} \mathrm{M}$, light source $=\mathrm{UV}$ light, light intensity $=$

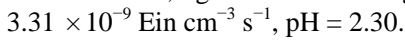

The absorption spectrum of MB during photodegradation is shown in Fig. 4.

\section{B. Effect of the Initial Concentration of Fe(III)-Aqua Complex}

Fig. 5 shows the effect of initial concentrations of $\mathrm{Fe}(\mathrm{III})$ ions on the photodegradation of MB under UV light. The concentration of $\mathrm{Fe}(\mathrm{III})$ solution was varied from $5.00 \times 10^{-4}$ $\mathrm{M}$ to $1.00 \times 10^{-3} \mathrm{M}$ at a regular interval, whereas the concentration of $\mathrm{MB}$ and light intensity were kept fixed at

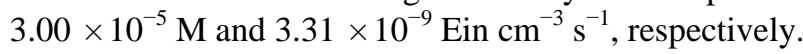

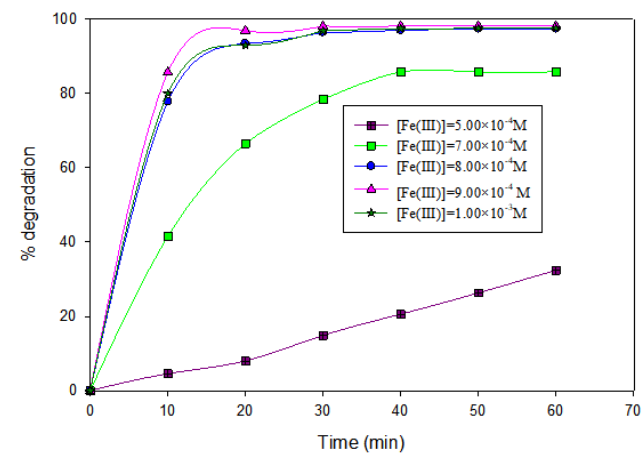

Fig. 5. Photodegradation of MB for various initial concentrations of Fe(III) aqueous solution. $[\mathrm{MB}]_{0}=3.00 \times 10^{-5} \mathrm{M}$, light source $=\mathrm{UV}$ light, Light intensity $=3.31 \times 10^{-9}$ Ein $\mathrm{cm}^{-3} \mathrm{~s}^{-1}$.

Fig. 5 reveals that $97.3 \%( \pm 0.8)$ degradation of MB was achieved within 30 min with an initial concentration of $\mathrm{Fe}(\mathrm{III})$ $\geq 8.00 \times 10^{-4} \mathrm{M}$, although the same level of degradation was found to take place for $[\mathrm{Fe}(\mathrm{III})]_{0}=9.00 \times 10^{-4} \mathrm{M}$ within 15 min time. It clearly indicates that the higher the concentration of $\mathrm{Fe}(\mathrm{III})$ ions, the faster the degradation kinetics. Higher concentration of $\mathrm{Fe}$ (III) ions facilitate more production of ${ }^{\circ} \mathrm{OH}$ radicals that initiate the degradation process. This result agrees well with the findings of $\mathrm{Li}$ et al [8]. At the lowest initial concentration of $\mathrm{Fe}(\mathrm{III})$, only $30 \%$ of degradation occurred in $60 \mathrm{~min}$ time. Because for this particular source, light intensity reaching the reaction mixture in the reactor is constant, the excess of $\mathrm{Fe}(\mathrm{III})$ ions remain ineffective at concentrations higher than $8.00 \times 10^{-4} \mathrm{M}$, and hence, a limiting value of degradation is reached at approximately $[\mathrm{Fe}(\mathrm{III})]_{0}=8.00 \times 10^{-4} \mathrm{M}$.

\section{Effect of the Initial Concentration of $M B$}

In order to determine the effect of initial dye concentration on the percent degradation of dye, experiments were carried out varying the initial concentration of MB from $1.50 \times 10^{-5}$ $\mathrm{M}$ to $3.50 \times 10^{-5} \mathrm{M}$, whereas the concentration of $\mathrm{Fe}(\mathrm{III})$ ions was kept fixed at $8.00 \times 10^{-4} \mathrm{M}$, and the $\mathrm{pH}$ of the solution was adjusted to 2.30. In each experiment, the reaction mixture was irradiated with UV light, keeping the intensity fixed at $3.31 \times 10^{-9} \mathrm{Ein}^{-3} \mathrm{~s}^{-1}$. The results are shown in Fig. 6.

As seen, the optimum condition of the initial concentration of $\mathrm{MB}$ is in the range of $2.50 \times 10^{-5} \mathrm{M}$ to $3.00 \times 10^{-5} \mathrm{M}$ for the nearly complete degradation $(\approx 97 \%)$ of the dye. As the initial concentration of $\mathrm{MB}$ is increased from $1.50 \times 10^{-5} \mathrm{M}$ to $3.00 \times 10^{-5} \mathrm{M}$, the percent degradation of the dye increased from $\approx 55 \%$ to $\approx 97 \%$. At the highest initial concentration of $3.50 \times 10^{-5} \mathrm{M}$, only $20 \%$ degradation took place in $60 \mathrm{~min}$ time, whereas $\approx 97 \%$ degradation occurred at the optimum 
condition of the initial concentration in $15 \mathrm{~min}$. The initial increase in degradation with increasing concentration of $\mathrm{MB}$ is due to the greater number of dye molecules available for ${ }^{\circ} \mathrm{OH}$. The decrease in degradation with an increase of dye concentration after the optimum value might be because a fixed amount of $\mathrm{Fe}(\mathrm{III})$ catalyst produces a fixed amount of ${ }^{\circ} \mathrm{OH}$ radicals, and these radicals can only attack a proportional amount of MB. This is consistent with the findings of Banat et al. [28] in their investigation of the photodegradation of $\mathrm{MB}$ dye in aqueous solution using a laboratory-scale UV lamp in the presence of $\mathrm{H}_{2} \mathrm{O}_{2}$. They suggested that when $\mathrm{MB}$ is present at a higher level in the reaction mixture, the available free radicals generated from a particular amount of catalyst are not adequate for the photodegradation process.

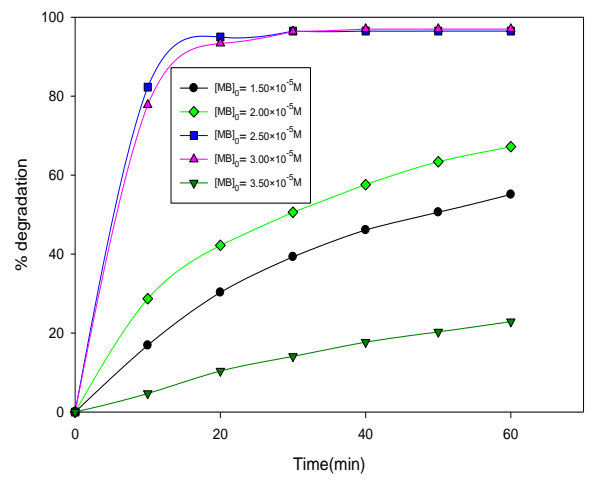

Fig. 6. Photodegradation of MB for various initial concentrations of MB. $[\mathrm{Fe}(\mathrm{III})]_{0}=8.00 \times 10^{-4} \mathrm{M}$, light source $=\mathrm{UV}$ light, light intensity $=3.31 \times$ $10^{-9}$ Ein $\mathrm{cm}^{-3} \mathrm{~s}^{-1}, \mathrm{pH}=2.30$.

\section{Effect of $p H$}

The effect of $\mathrm{pH}$ on the photodegradation of $\mathrm{MB}$ in the presence of $\mathrm{Fe}(\mathrm{III})$-aqua complex as a photocatalyst under UV irradiation was investigated, and the results are shown in Fig. 7.

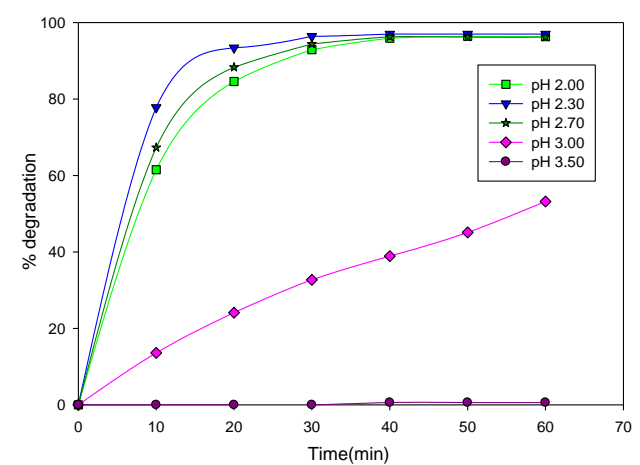

Fig. 7. Photodegradation of $\mathrm{MB}$ at various $\mathrm{pH}$. $[\mathrm{MB}]_{0}=3.00 \times 10^{-5} \mathrm{M}$, $[\mathrm{Fe}(\mathrm{III})]_{0}=8.00 \times 10^{-4} \mathrm{M}$, light source $=\mathrm{UV}$ light, light intensity $=3.31 \times$

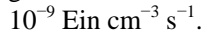

$\mathrm{Fe}(\mathrm{III})$ ions are well known to form precipitate at a $\mathrm{pH}$ higher than 3.50. So the photodegradation of MB dye was investigated over the $\mathrm{pH}$ range of 2.00-3.50 while keeping all other variables - initial concentration of $\mathrm{MB}$ and $\mathrm{Fe}(\mathrm{III})$ solution, light source, and light intensity - constant. Fig. 7 reveals that $97 \%$ of degradation occurred between $\mathrm{pH} 2.00$ and 2.70 within $40 \mathrm{~min}$ time. However, at $\mathrm{pH} 2.00$, photodegradation is slightly slower than that at $\mathrm{pH} 2.30$. The most rapid and maximum degradation was observed at $\mathrm{pH}$ 2.30, which might be due to the production of the highest concentration of $\left[\mathrm{Fe}(\mathrm{OH})\left(\mathrm{H}_{2} \mathrm{O}\right)_{5}\right]^{2+}$ species that eventually makes ${ }^{\circ} \mathrm{OH}$ radical more available. No photodegradation was observed at $\mathrm{pH} 3.50$, which is likely due to precipitation of $\mathrm{Fe}(\mathrm{OH})_{3}$. Our result agrees well with the findings of Hossain et al. [29] who investigated the photocatalytic effect of $\mathrm{Fe}(\mathrm{III})-$ aqua complex on photodegradation of orange green dye. They reported that maximum degradation occurred at pH 2.5.

\section{E. Effect of Light Sources on Photodegradation}

A mixture of an aqueous solution of MB $\left(3.00 \times 10^{-5} \mathrm{M}\right)$ and $\mathrm{Fe}(\mathrm{III})\left(8.00 \times 10^{-4} \mathrm{M}\right)$ was exposed to natural sunlight. The reaction mixture was also irradiated with UV light (3.31 $\times 10^{-9}$ Ein $\mathrm{cm}^{-3} \mathrm{~s}^{-1}$ ) and visible light. The $\mathrm{pH}$ of the reaction mixture was kept fixed at 2.30 in all three experiments. Fig. 8 represents the comparison of the percent degradation of $\mathrm{MB}$ that occurred in three different light sources.

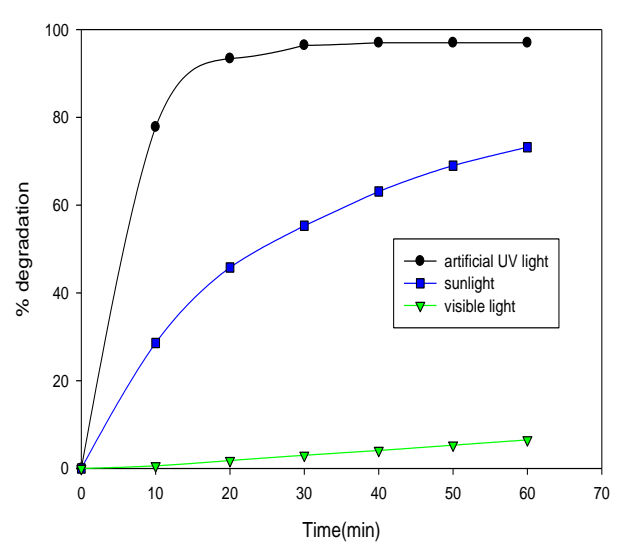

Fig. 8. Photodegradation of MB for various light sources. $[\mathrm{MB}]_{0}=3.00 \times$ $10^{-5} \mathrm{M},[\mathrm{Fe}(\mathrm{III})]_{0}=8.00 \times 10^{-4} \mathrm{M}$ and $\mathrm{pH}=2.3$.

It is seen that the degradation of $\mathrm{MB}$ dye in visible light is negligible after irradiating the reaction mixture for $60 \mathrm{~min}$. But when the reaction mixture was irradiated with UV light, approximately $97 \%$ of the dye was degraded after $30 \mathrm{~min}$. This is because the absorption of UV photons induced the photocatalytic reaction of MB [30]. It has been reported [24] that upon irradiation at $365 \mathrm{~nm}$, the light is absorbed by Fe(III) species and thus facilitates the formation of ${ }^{\circ} \mathrm{OH}$ radicals. Under sunlight, approximately $73 \%$ degradation of the MB dye occurred within 60 min. In comparison, approximately $50 \%$ degradation of tributyltin chloride (TBT) in a mixture of TBT and Fe(III) solution was found to occur in solar light after $2 \mathrm{~h}[20]$.

\section{F. Effect of Intensity of UV Light}

Because maximum degradation was observed under the UV light source as shown in Fig. 8, the effect of UV light intensity on photodegradation of $\mathrm{MB}$ was investigated. The

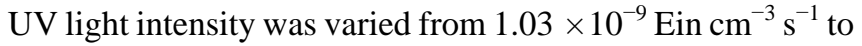
$3.31 \times 10^{-9} \mathrm{Ein}^{-3} \mathrm{~s}^{-1}$ at a regular interval. Concentrations of $\mathrm{MB}$ and $\mathrm{Fe}(\mathrm{III})$ aqueous solution were fixed at $3.00 \times 10^{-5}$ $\mathrm{M}$ and $8.00 \times 10^{-4} \mathrm{M}$, respectively, and the $\mathrm{pH}$ of the solution was maintained at 2.30. The results are shown in Fig. 9. 


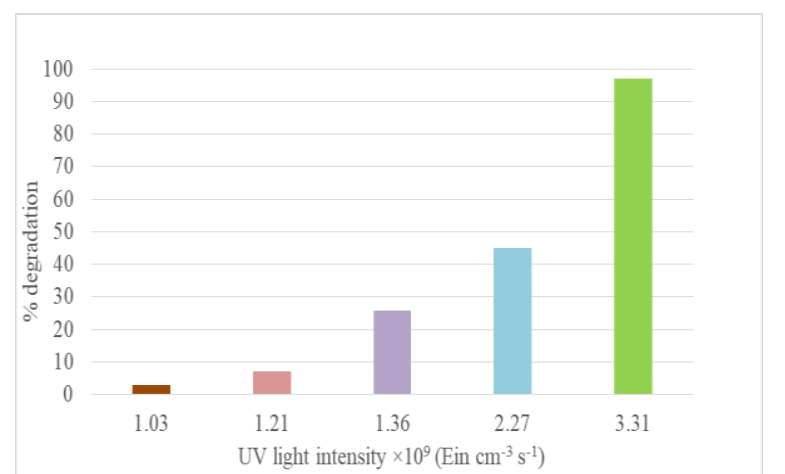

Fig. 9. Photodegradation of MB for various intensities of UV light. $[\mathrm{MB}]_{0}=$ $3.00 \times 10^{-5} \mathrm{M},[\mathrm{Fe}(\mathrm{III})]_{0}=8.00 \times 10^{-4} \mathrm{M}$ and $\mathrm{pH}=2.30$.

With the increase of light intensity, the number of photons also increases, which enhances the production of ${ }^{\circ} \mathrm{OH}$ radicals. A higher amount of $\mathrm{OH}$ radicals causes more efficient degradation. Hence, Fe(III)-aqua complex-mediated photodegradation increases with the increase in the intensity of UV light.

\section{CONCLUSIONS}

$\mathrm{Fe}(\mathrm{III})$ photoinduced degradation was found to be affected by various parameters such as concentration of $\mathrm{Fe}$ (III) ions and $\mathrm{MB}$ dye, $\mathrm{pH}$, the intensity of UV light, and the type of light source.

In the $\mathrm{Fe}$ (III) aqueous system, with increasing initial concentration of $\mathrm{Fe}(\mathrm{III})$ solution, the percent degradation of MB increased and reached a limiting value at $8.00 \times 10^{-4} \mathrm{M}$. With increasing initial concentration of dye, degradation was found to increase, reach an optimum value of $3.00 \times 10^{-5} \mathrm{M}$, and then decrease. The degradation process was found to be efficient at lower $\mathrm{pH}$, and maximum degradation occurred at pH 2.30 .

Percentage degradation of $97 \%$ of $\mathrm{MB}$ was found by irradiation in UV light for $60 \mathrm{~min}$. In comparison, 73\% degradation of the dye was observed under sunlight with the same reaction conditions. Hence, it can be concluded that the MB dye can be readily degraded using Fe(III)-aqua complex as photocatalyst if kept under sunlight for a longer period of time without the use of any expensive UV light source. Therefore, this process is much more environment friendly and cost-effective. Negligible percentage degradation of the dye was observed under visible light.

The concentration of $\mathrm{Fe}$ (III) used in the process to achieve maximum degradation is quite low, so the treated solution can be expected to be compatible with the aquatic environment. The acidity of the treated effluent can easily be neutralized using sodium bicarbonate solution. Thus, in recent times when environmental deterioration is rapidly becoming the cause of utmost concern to humankind, this photocatalytic system could be a useful technology for the mineralization of $\mathrm{MB}$ and similar dyes and limit water pollution to some extent.

\section{CONFLICT OF INTEREST}

The authors declare no conflict of interest

\section{AUTHOR CONTRIBUTIONS}

Ashfeen Nawar conducted the laboratory work, analyzed the data, and wrote the paper. Md. Ataur Rahman cosupervised the research work. Md. Mufazzal Hossain supervised the research and reviewed the paper. All authors approved the final version.

\section{REFERENCES}

[1] Z. Carmen and S. Daniela, Organic Pollutants Ten Years after the Stockholm Convention - Environmental and Analytical Update, London, IntechOpen, 2012, ch. 3, pp. 55-86.

[2] S. K. A. Solmaz, A. Birgul, G. E. Vstun, and T. Yonar, "Colour and COD removal from textile effluent by coagulation and advanced oxidation processes, society of dyers and colourists," Color Technol, vol. 122, pp. 102-109, 2006.

[3] B. M. Altahir, W. Feng, H. H. Jasim, K. E. Taylor, N. Biswas, J. K. Bewatra, and S. A. A. Jassim, "Soybean peroxidase-catalysed removal of benzidines from water," Journal of Environmental Engineering and Science, vol. 10, no. 4, pp. 73-80, 2015.

[4] O. J. Hao, H. Kim, and P. C. Chang, "Decolorization of wastewater," Critical Reviews in Environmental Science and Technology, vol. 30, pp. 449-505, 2000.

[5] Y. Anjaneyulu, C. N. Sreedhara, and R. D. S. Suman, "Decolourization of industrial effluents - available methods and emerging technologies a review," Reviews in Environmental Science and Bio/Technology, vol. 4, pp. 245-273, 2005.

[6] T. Robinson, G. McMullan, R. Marchant, and P. Nigam, "Remediation of dyes in textile effluent: A critical review on current treatment technologies with a proposed alternative," Bioresour Technol, vol. 77, no. 3, pp. 247-255, 2001

[7] Y. Honghui, Y. Chen, and L. Guo, "Homogenous photocatalytic decomposition of acetic acid using UV-Fe2+/Fe3+ system in the absence of oxygen," Catalysis Communication, vol. 11, pp. 1099-1103, 2010.

[8] L. Mengkai, Z. Qiang, C. Pulgarin, and J. Kiwi, "Accelerated methylene blue (MB) degradation by Fenton reagent exposed to UV or VUV/UV light in an innovative micro photo-reactor," Applied Catalysis B: Environmental, vol. 187, pp. 83-89, 2016.

[9] F. Zhang, J. Zhao, T. Shen, H. Hidaka, E. Pelizzetti, and N. Serpone, "TiO2-assisted photodegradation of dye pollutants II. Adsorption and degradation kinetics of eosin in $\mathrm{TiO} 2$ dis- persions under visible light irradiation," Applied Catalysis B: Environmental, vol. 15, pp. 147-156, 1998.

[10] H. Dong, G. Zeng, L. Tang, C. Fan, C. Zhang, X. He, and Y. He, “An overview on limitations of $\mathrm{TiO} 2$-based particles for photocatalytic degradation of organic pollutants and the corresponding countermeasures," Water Research, vol. 79, pp. 128-146, 2015.

[11] I. Arslan and I. A. BalcioPğlu, "Degradation of commercial reactive dyestuffs by heterogeneous and homogenous advanced oxidation processes: A comparative study," Dyes and Pigments, vol. 43, pp. 95-108, 1999.

[12] V. A. Simion, I. Cretescu, D. Lutic, C. Luca, and I Poulios, "Enhancing the fenton process by UV light applied in textile wastewater treatment," Environmental Engineering and Management Journal, vol. 14, no. 3, pp. $595-600,2015$.

[13] B. H. Diya'uddeen, A. R. A. Aziz, and W. M. A. W. Daud, "On the limitation of fenton oxidation operational parameters: A review," International Journal of Chemical Reactor Engineering, vol. 10, pp. 1-25, 2012.

[14] M. Brienza and I. A. Katsoyiannis, "Sulfate radical technologies as tertiary treatment for the removal of emerging contaminants from wastewater," Sustainability, vol. 9, no. 9, 1604, 2017.

[15] N. Brand, G. Mailhot, and M. Bolte, "Degradation photoinduced by $\mathrm{Fe}$ (III): Method of alkylphenol ethoxylates removal in water," Environ Sci Technol, vol. 32, no. 18, pp. 2715-2720, 1998.

[16] O. Bajt, G. Mailhot, and M. Bolte, "Degradation of dibutyl phthalate by homogeneous photocatalysis with Fe(III) in aqueous solution," Applied Catalysis B: Environmental, vol. 33, no. 3, pp. 239-248, 2001.

[17] D. Wan, J. Zuo, Y. Chen, Q. Chen, and Y. Zuo, "Photodegradation of amitriptyline in $\mathrm{Fe}(\mathrm{III})$-citrate-oxalate binary system: Synergistic effect and mechanism," Chemosphere, vol. 210, pp. 224-231, 2018.

[18] J. Zhao, Y. Jiang, M. Kong, G. Liu, and D. D. Dionysiou, "Fe(III)-oxalate complex mediated phosphate released from diazinon photodegradation: Pathway signatures based on oxygen isotopes," Jounal of Hazardous Materials, vol. 358, pp. 319-326, 2018. 
[19] Y. E. Tyutereva, P. S. Sherin, E. V. Poliakova, O. S. Koscheeva, V. P. Grivin, V. F. Plyusnin, O. V. Shuvaeva, and I. P. Pozdnyakov, "Photodegradation of para-arsanilic acid mediated by photolysis of iron(III) oxalate complexes," Chemosphere, vol. 261, pp. 1-7, 2020.

[20] G. Mailhot, M. Astruc, and M. Bolte, "Degradation of tributyltin chloride in water photoinduced by iron(III)," Appl Organometal Chem, vol. 13, no. 1, pp. 53-61, 1999.

[21] B. C. Faust and J. Hoigne, "Photolysis of Fe(III)-hydroxy complexes as sources of $\mathrm{OH}$ radicals in clouds, fog and rain," Atmospheric Environment, vol. 24A, no. 1, pp. 79-89, 1990.

[22] Z. Zhe, W. Feng, and D. Nansheng, "Photochemical reduction of $\mathrm{Cr}(\mathrm{VI})$ in aqueous solutions containing $\mathrm{Fe}(\mathrm{III})$-hydroxy complexes," Toxicological \& Environmental Chemistry, vol. 82, no. 3-4, pp. 129-137, 2002.

[23] L. Qian, Q. Wang, W. Deng, L. Gong, A. Dong, C. Liu, R. Dai, X. Huang, and $\mathrm{Z}$. Huang, "Highly effective $\mathrm{CuO}$ catalysts synthesized by various routes for discoloration of methylene blue," Chem Pap, vol. 74 , pp. 1113-1121, 2019.

[24] S. N. M. Suhaimy and L. C. Abdullah, "Removal of methylene blue from aqueous solution by using electrical arc furnace (EAF) slag," Indones. J. Chem., vol. 20, no. 1, pp. 113-119, 2020.

[25] A. Houas, H. Lachheb, M. Ksibi, E. Elaloui, C. Guillard, and J. M. Herrmann, "Photocatalytic degradation pathway of methylene blue in water," Applied Catalysis B: Environmental, vol. 31, pp. 145-157, 2001.

[26] M. M. Hasan, "A comparative study of photodegradation of a textile dye orange $\mathrm{G}$ by $\mathrm{Fe}$ (III) aqua-complex and fenton process," MS Thesis, Department of Chemistry, University of Dhaka, Bangladesh, 2017.

[27] O. A. Yildirim, H. Arslan, and S. Sönmezoğlu, "Facile synthesis of cobalt-doped zinc oxide thin films for highly efficient visible light photocatalysts," Applied Surface Science, vol. 390, pp. 111-121, 2016.

[28] F. Banat, S. Al-Asheh, M. Al-Rawashdeh, and M. Nusair, "Photodegradation of methylene blue dye by the UV/H2O2 and UV/acetone oxidation processes," DESALINATION, vol. 181, pp. 225-232, 2005.

[29] M. M. Hossain, M. R. I. Rasel, and M. S. Islam MS, "Photodegradation of orange green by Fe(III) aqua complex," Dhaka Univ J of Sci, vol. 60, no. 1 , pp. 43-46, 2012.

[30] J. Tschirch, R. Dillert, D. Bahnemann, B. Proft, A. Biedermann, and B. Goer, "Photodegradation of methylene blue in water, a standard method to determine the activity of photocatalytic coatings," Res Chem Intermed, vol. 34, pp. 381-392, 2008.

Copyright $\odot 2021$ by the authors. This is an open access article distributed under the Creative Commons Attribution License which permits unrestricted use, distribution, and reproduction in any medium, provided the original work is properly cited (CC BY 4.0).

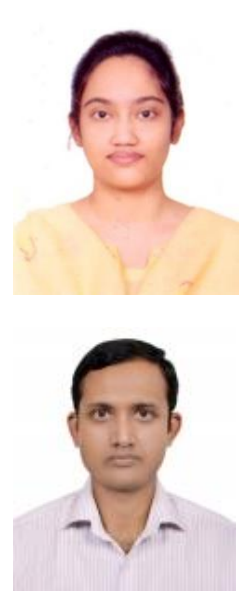

\begin{abstract}
Ashfeen Nawar was born in Dhaka, Bangladesh. She earned her BS (honours) in chemistry from the University of Dhaka, Dhaka, Bangladesh, in 2019. She is currently pursuing her MS in physical chemistry at the University of Dhaka, Dhaka, Bangladesh. Her research interests include photocatalysis and photodegradation.
\end{abstract} Properties of Prepared Copper(II) Oxide was published in the Dhaka University Journal of Science, vol.68, no.1, pp.7-12, in 2020. His research interests include adsorption, photodegradation, and synthesis of photocatalyst.

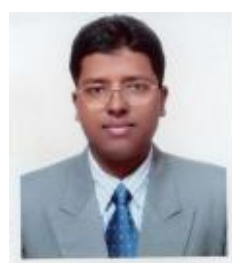

Md. Mufazzal Hossain was born in Bangladesh. He completed his BSc (honours) in chemistry in 1991 and MSc in physical-inorganic chemistry in 1992 from the University of Dhaka, Dhaka, Bangladesh. $\mathrm{He}$ earned his $\mathrm{PhD}$ in material science and engineering from the Utsunomiya University, Japan, in 2001. He is currently working as professor at the Department of Chemistry, University of Dhaka,

Dhaka, Bangladesh.

His paper on Theoretical Investigation of Non-linear Optical (NLO) properties and UV-visible Spectra of N-(3,5-dichlorobenzylidene)aniline and $\mathrm{N}$-(3,5-dichlorobenzylidene)4-nitroaniline was published in Dhaka Univ. J. Sci., vol.66, pp.139-143 in 2018. He was the co-author of the paper Enhanced Photocatalytic Activity of an Acid-modified $\mathrm{TiO}_{2}$ Surface for Degradation of the Azo Dye Remazol Red published in Chemistry Select. 2017, 2, pp.10371-10374. His research interests include Preparation and Characterization of Monolayer and LB film, investigation of different adsorption, and photodegradation methods for the treatment of dye containing wastewater. 